\title{
Validity of 24-h recalls in (pre-)school aged children: Comparison of proxy-reported energy intakes with measured energy expenditure.
}

Citation for published version (APA):

Bornhorst, C., Bel Serrat, S., Pigeot, I., Huybrechts, I., Ottavaere, C., Sioen, I., De Henauw, S., Mouratidou, T., Mesana, M. I., Westerterp, K., Bammann, K., Lissner, L., Eiben, G., Pala, V., Rayson, M., Krogh, V., \& Moreno, L. A. (2014). Validity of 24-h recalls in (pre-)school aged children: Comparison of proxy-reported energy intakes with measured energy expenditure. Clinical Nutrition, 33(1), 79-84. https://doi.org/10.1016/j.clnu.2013.03.018

Document status and date:

Published: 01/02/2014

DOI:

10.1016/j.clnu.2013.03.018

Document Version:

Publisher's PDF, also known as Version of record

Document license:

Taverne

Please check the document version of this publication:

- A submitted manuscript is the version of the article upon submission and before peer-review. There can be important differences between the submitted version and the official published version of record.

People interested in the research are advised to contact the author for the final version of the publication, or visit the DOI to the publisher's website.

- The final author version and the galley proof are versions of the publication after peer review.

- The final published version features the final layout of the paper including the volume, issue and page numbers.

Link to publication

\footnotetext{
General rights rights.

- You may freely distribute the URL identifying the publication in the public portal. please follow below link for the End User Agreement:

www.umlib.nl/taverne-license

Take down policy

If you believe that this document breaches copyright please contact us at:

repository@maastrichtuniversity.nl

providing details and we will investigate your claim.
}

Copyright and moral rights for the publications made accessible in the public portal are retained by the authors and/or other copyright owners and it is a condition of accessing publications that users recognise and abide by the legal requirements associated with these

- Users may download and print one copy of any publication from the public portal for the purpose of private study or research.

- You may not further distribute the material or use it for any profit-making activity or commercial gain

If the publication is distributed under the terms of Article $25 \mathrm{fa}$ of the Dutch Copyright Act, indicated by the "Taverne" license above, 
Original article

\title{
Validity of 24-h recalls in (pre-)school aged children: Comparison of proxy-reported energy intakes with measured energy expenditure $\mathrm{s}^{\text {访访 }}$
}

\author{
C. Börnhorst ${ }^{\mathrm{a}, \mathrm{k}}$, S. Bel-Serrat ${ }^{\mathrm{b}, \mathrm{k}}$, I. Pigeot $^{\mathrm{a}}$, I. Huybrechts $^{\mathrm{c}, \mathrm{d}}$, C. Ottavaere $^{\mathrm{c}}$, I. Sioen $^{\mathrm{c}}$, \\ S. De Henauw ${ }^{\text {c,e }}$, T. Mouratidou ${ }^{b}$, M.I. Mesana ${ }^{b}$, K. Westerterp ${ }^{\text {, }}$, K. Bammann ${ }^{\text {a,g }}$, \\ L. Lissner $^{\text {h }}$, G. Eiben ${ }^{\text {h }}$, V. Pala ${ }^{i}$, M. Rayson ${ }^{j}$, V. Krogh ${ }^{i}$, L.A. Moreno ${ }^{\text {, } *}$, on behalf of the \\ IDEFICS consortium
}

\author{
a BIPS - Institute for Epidemiology and Prevention Research, Bremen, Germany \\ ${ }^{\mathrm{b}}$ GENUD (Growth, Exercise, Nutrition and Development) Research Group, Faculty of Health Sciences, University of Zaragoza, Zaragoza, Spain \\ ${ }^{\mathrm{c}}$ Department of Public Health, Ghent University, Ghent, Belgium \\ ${ }^{\mathrm{d}}$ Dietary Exposure Assessment Groups, International Agency for Research on Cancer, Lyon, France \\ e University College Ghent, Department of Nutrition and Dietetics, Faculty of Health Care "Vesalius", Ghent, Belgium \\ ${ }^{\mathrm{f}}$ Department of Human Biology, Maastricht University, The Netherlands \\ ${ }^{\mathrm{g}}$ Institute for Public Health and Nursing Research, University of Bremen, Bremen, Germany \\ ${ }^{\mathrm{h}}$ Department of Public Health and Community Medicine, University of Gothenburg, Gothenburg, Sweden \\ ${ }^{\mathrm{i}}$ Department of Preventive and Predictive Medicine, Nutritional Epidemiology Unit, Fondazione IRCSS Istituto Nazionale dei Tumori, Milan, Italy \\ ${ }^{\mathrm{j}}$ BioTel Ltd. Clifton, Clifton, Bristol, United Kingdom
}

\section{A R T I C L E I N F O}

\section{Article history:}

Received 26 July 2012

Accepted 24 March 2013

\section{Keywords:}

Child

Doubly labeled water

Energy expenditure

Energy intake

\begin{abstract}
S U M M A R Y
Background $\mathcal{E}$ aims: Little is known about the validity of repeated 24-h dietary recalls (24-HDR) as a measure of total energy intake (EI) in young children. This study aimed to evaluate the validity of proxyreported EI by comparison with total energy expenditure (TEE) measured by the doubly labeled water (DLW) technique.

Methods: The agreement between EI and TEE was investigated in 36 (47.2\% boys) children aged 4-10 years from Belgium and Spain using subgroup analyses and Bland-Altman plots. Low-energy-reporters (LER), adequate-energy-reporters (AER) and high-energy-reporters (HER) were defined from the ratio of EI over TEE by application of age- and sex-specific cut-off values.

Results: There was good agreement between means of EI (1500 kcal/day) and TEE (1523 kcal/day) at group level though in single children, i.e. at the individual level, large differences were observed. Almost perfect agreement between EI and TEE was observed in thin/normal weight children(EI: $1511 \mathrm{kcal} / \mathrm{day}$; TEE: $1513 \mathrm{kcal} /$ day). Even in overweight/obese children the mean difference between EI and TEE was only $-86 \mathrm{kcal} /$ day. Among the participants, 28 (78\%) were classified as AER, five (14\%) as HER and three (8\%) as LER.

Conclusion: Two proxy-reported 24-HDRs were found to be a valid instrument to assess EI on group level but not on the individual level.
\end{abstract}

(c) 2013 Elsevier Ltd and European Society for Clinical Nutrition and Metabolism. All rights reserved.

\footnotetext{
Abbreviations: EI, energy intake; TEE, total energy expenditure; DLW, doubly labelled water; 24-HDR, 24-h dietary recall; LER, low-energy-reporters; HER, highenergy-reporters; AER, adequate energy reporters.

औ 1 . Jahrestagung der Deutschen Gesellschaft für Medizinische Informatik, Biometrie und Epidemiologie (GMDS) und der Deutschen Gesellschaft für Epidemiologie (DGEpi). Mainz (Germany), 2011.

解 2 2. 11 th European Nutrition Conference (FENS). Madrid (Spain), 2011.

* Corresponding author. Faculty of Health Sciences, University of Zaragoza, C/ Domingo Miral, s/n, 50009 Zaragoza, Spain. Tel.: +34 9767610 00x4457; fax: +34 976761752.

E-mail address: Imoreno@unizar.es (L.A. Moreno).

${ }^{\mathrm{k}}$ C. Börnhorst and S. Bel-Serrat contributed equally to this manuscript.
}

\section{Introduction}

Dietary intake has been recognized to be related not only to normal growth, but also to the development and progression of chronic diseases that start early in life. ${ }^{1}$ However, accurate assessment of dietary information is problematic - especially among children. ${ }^{2-5}$ These lack the ability to report their own intake, so that data in children younger than seven years mainly rely on proxyreports. ${ }^{6}$ Furthermore, children's diets tend to be highly variable from day-to-day and their food habits change rapidly during childhood which makes dietary assessment a challenging issue. ${ }^{7}$ 
The validity of a dietary assessment method can be evaluated by comparing reported energy intake (EI) to measured total energy expenditure (TEE) $)^{5}$ because TEE and EI can be assumed to be equal for individuals in energy balance. ${ }^{3}$ This assumption is also justified in children as energy cost of growth and development during childhood is very small, i.e. $1-2 \%{ }^{4}$ Doubly labeled water (DLW) is considered the "gold-standard" method to assess TEE. ${ }^{2}$

Validation studies with DLW in children and adolescents have shown self-reported (partly with parental assistance) 24-h dietary recalls (24-HDR) to be a valid measure of EI at least on group level, though misreporting of EI is a common problem especially in overweight/obese study populations. ${ }^{8}$ Results concerning misreporting in children and adolescents vary widely among studies (underreporting from $19 \%$ to $41 \%$; overreporting from $7 \%$ to $11 \%$ of reported EI $)^{9}$ and yet it is unknown whether the study participants' weight status is predictive for misreporting in data relying on proxy-reports as well. Moreover overweight/obese study subjects may be more likely than thin/normal weight subjects to be on an energy-restricted diet, i.e. to actually eat less than physiologically required (EI < TEE; undereating) which complicates the evaluation of reported EI. Apart from total EI, nutrient intakes such as fat, sugar or micronutrients are commonly misreported which was shown to result in flawed associations between food/nutrient intakes and body weight. $^{10}$

To date, little is known about the validity of 24-HDR data obtained by parents acting as surrogate reporters. Therefore the present study aims to investigate the validity of 24-HDR data in four-to-ten-year-old children by comparison of proxy-reported EI with objectively measured TEE.

\section{Materials and methods}

\subsection{Sample}

The present validation study was conducted within the framework of the IDEFICS ("Identification and prevention of dietary- and lifestyle- induced health effects in children and infants") study from October 2008 to July 2009. It is based on a convenience sample of four-to-ten-year-old children from three different centres (Belgium, Sweden, Spain). ${ }^{11}$ The burden for participating children and their parents was deemed to be too high to justify a random sample. Belgium and Spain recruited children through schools, newspapers or by asking colleagues or friends. In contrast, a subgroup of ten obese Swedish children was recruited from an obesity clinic which underwent the same protocol. Although these children were weight stable at the time of the validation study, they were excluded from the main analysis presented here as they were selected from a clinical setting and hence this would have limited the generalisability of the results. The Swedish children were considered in a subgroup analysis only.

Furthermore, only children with complete information on age, sex, height, weight, at least two 24-HDR as well as DLW measurements were included in the present study resulting in 36 children (six from Belgium, thirty from Spain). The study was approved by the appropriate local ethics committees in each centre and written informed consent was obtained from the parents before participation.

\subsection{Total energy expenditure measurement}

TEE was measured over a nine-day period (from Day -1 to Day 8 ) by means of DLW following the Maastricht protocol. ${ }^{12}$ The measurement schedule is summarised in Fig. 1. Each child was given a single oral dose of DLW based on his/her body weight $(\mathrm{ml} \mathrm{DLW} / \mathrm{kg})$, increasing background levels of Oxygen-18 with

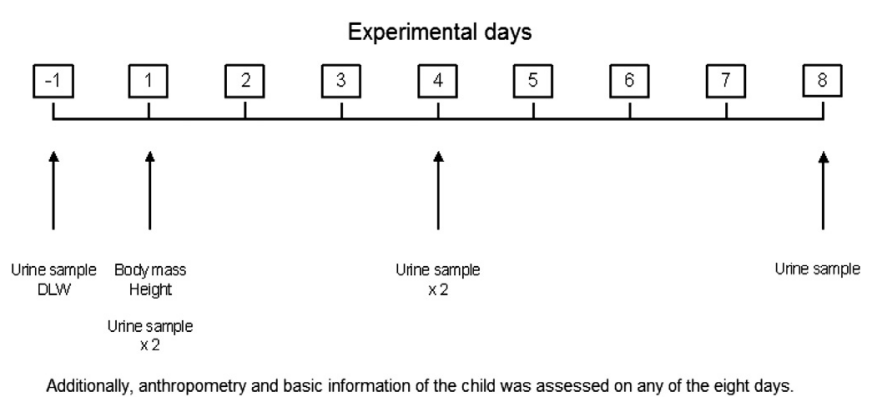

Fig. 1. Measurement schedule of the IDEFICS validation study. ${ }^{11}$

250-300 parts per million (ppm) and background levels of Deuterium with 125-150 ppm. Urine samples were obtained from each child several minutes (maximum 15 min) before ingesting the DLW dose (baseline urine), and on Days 1, 4, and 8 after the DLW dose. Each urine sample was collected at the same time of the day $( \pm 1 \mathrm{~h})$ in all children depending on their timetable and physiological needs. Parents were asked to record the collection time for each urine sample. After collection of urine samples, $2 \mathrm{ml}$ from each urine sample were transferred into two individual glass vials and kept frozen at $-20^{\circ} \mathrm{C}$ at each study centre. Urine samples were sent as one batch directly from all centres to the central laboratory at the end of data collection. Samples were analysed by isotope ratio mass spectrometry with an analytic precision of $0.2 \mathrm{ppm}$ for ${ }^{2} \mathrm{H}$ isotope and $0.4 \mathrm{ppm}$ for ${ }^{18} \mathrm{O}$ isotope. All analytical tests were performed in the Human Biology Department, University of Maastricht (The Netherlands). The value of 0.85 was used as an estimate of the respiratory quotient, based on the consumption of a standard Western diet, ${ }^{13}$ and TEE was calculated according to Schoeller et al. ${ }^{13}$

\subsection{Energy intake measurement}

During the DLW measurement period at least two 24-HDR per child were recorded. EI was assessed using a computerised 24-HDR called SACINA (Self Administered Children and Infants Nutrition Assessment) that is based on the previously designed software YANA-C developed and validated for Flemish adolescents. ${ }^{14}$ Within the framework of the IDEFICS study, this 24-HDR was adapted for assessment of proxy-reported dietary intakes in young children. ${ }^{15}$ The SACINA is structured according to six meal occasions (breakfast, morning snack, lunch, afternoon snack, dinner, evening snack) embedded within chronological questions related to daily activities aiming to help proxies, mainly the parents, to recall their child's intakes of the previous day. ${ }^{14}$ Portion sizes were assessed by photos of serving sizes, standard portions, customary packing size and foods in pieces or slices that were displayed on the screen. For every meal, parents were asked to select all food items their child had eaten at the specific occasion and, for each item, the respondents typed the amount consumed or modified the standard serving size with two command buttons (more/less).

The 24-HDR interviews were completed by proxies under supervision of fieldwork personnel. On weekdays, school meals were additionally assessed either through parents or by means of direct observation $(N=18)$. In the latter case, data was documented by survey personnel using pre-defined recording sheets specifically designed for that purpose. Based on these sheets, the observer indicated the amount eaten by the child. Pre-defined portion sizes ranged from "nothing”, “ $1 / 4$ portion”, “ $1 \frac{1}{2}$ portion”, "1 portion”, “1 1/2 portions", "2 portions" up to "more than 2 portions". Different standard measures like hands-full, slices, table spoons, etc. were given depending on the regarded food item. School meal data 
were merged with the parentally reported 24-HDR data to enhance completeness of dietary intakes. Although up to three repeated 24-HDR were carried out on non-consecutive days, only two recalls per child were used in the current analyses to achieve an equal number of 24-HDR per child. In general, the first and second recall day was used. If both recalls were assessed on a weekday but the third one on a weekend day, the weekend day was chosen to increase the number of children having one weekday and one weekend day. The remaining weekday was selected randomly in such cases.

Energy and nutrient intakes were obtained using countryspecific Food Composition Tables (FCTs) ${ }^{15}$ due to the lack of a panEuropean FCT. Common guidelines and procedures to prevent and minimize bias were adopted to harmonise nutrient databases across countries. Nutrient values were also harmonized using the documentation of the country-specific food components. In detail, the FCTs used were "Centre d'Ensenyament Superior de Nutrició I Dietètica (CESNID). Tablas de composición de alimentos del CESNID, 2nd edn. Madrid: McGraw-Hill Interamericana, 2004" in Spain, "NUBEL. Belgian Food Composition Table, 4th edn. Brussels: Ministry of Public Health, 2004" in Belgium and "Swedish National Food Agency (SNFA). Swedish Food Database (available at http://www.slv. se/en-gb/Group1/Food-and-Nutrition/The-Food-Database/)" in Sw eden. EI (kcal/day) and macronutrient intakes (carbohydrates, protein, fat in g/day) were calculated as mean of the two 24-HDR for each child. Macronutrient intakes were additionally expressed as percentage of total EI derived from carbohydrates, proteins and fat.

\subsection{Anthropometric measurements}

Height was measured to the nearest $0.1 \mathrm{~cm}$ with a calibrated stadiometer (Telescopic height measuring instruments SECA 225, Birmingham, UK). Body weight was measured in light underwear on a calibrated scale accurate to $0.1 \mathrm{~kg}$ on the first and last day of the measurement period (TANITA BC 420 SMA digital weighing scale, Tanita Europe GmBH, Sindelfingen, Germany). Body mass index (BMI) was calculated by dividing body mass in kg measured at Day 1 (if missing, the measurement of the last day was used) by the squared body height in meters. BMI was categorised according to the International Obesity Task Force (IOTF) criteria ${ }^{16}$ and BMI zscores were calculated according to Cole et al. ${ }^{17}$ For most analyses, thin/normal weight and overweight/obese children were each combined into one group.

\subsection{Statistical analysis}

Analyses were done for all children as well as stratified by study centre, sex, weight status (thin/normal weight vs. overweight/ obese) and age group ( 4 to $<6$ years vs. 6 to $<10$ years). Only one of the mentioned variables was considered at the same time due to the small number of children per strata. The Bland-Altman plot ${ }^{18}$ was used to assess the agreement between EI and TEE. This method calculates a bias as mean difference between the reference method (TEE) and the reported value (EI). Limits of agreement are calculated as bias \pm 2 SD of this observed bias. In the following, the term 'bias' always refers to the difference between EI and TEE unless another specification is given.

Following the approach of Sjoberg et al. ${ }^{19}$ the ratio of EI over TEE was used to differentiate adequate-energy-reports (AER) from lowenergy-reports (LER) and high-energy-reports (HER). Participants were classified as AER, LER or HER based on $95 \%$ confidence limits (CL) of the expected ratio EI over TEE, which equals 1.00 under the assumption of energy balance. CLs were calculated according to the following formula ${ }^{20}$ :

$95 \% \mathrm{CL}_{l, u}= \pm 1.96 \cdot \sqrt{\frac{\left(\mathrm{CV}_{\mathrm{EI}}\right)^{2}}{d}+\left(\mathrm{CV}_{\mathrm{TEE}}\right)^{2}}$

Child-specific reference values (boys: $22.5 \%$, girls $21.3 \%$ ) based on previous literature were used for the coefficient of variation for daily EI $\left(\mathrm{CV}_{\mathrm{EI}}\right){ }^{21}$ The number of days (d) was set to two and for the coefficient of variation of TEE $\left(\mathrm{CV}_{\mathrm{TEE}}\right)$ the value $8.2 \%$ was chosen. ${ }^{20}$

Children were defined as AER, LER and HER according to the cutoff values calculated by insertion of the reference values in the above formula (LER: boys: $\mathrm{EI} / \mathrm{TEE}<0.65$, girls: $\mathrm{EI} / \mathrm{TEE}<0.66$; AER: boys: $0.65 \leq \mathrm{EI} / \mathrm{TEE}<1.35$, girls: $0.66 \leq \mathrm{EI} / \mathrm{TEE}<1.34$; HER: boys: $\mathrm{EI} /$ $\mathrm{TEE} \geq 1.35$, girls $\mathrm{EI} / \mathrm{TEE} \geq 1.34$ ).

Macronutrient intakes as well as TEE, EI and study participants' characteristics were compared between groups of AER, LER and HER.

All analyses were performed using the statistical software package SAS (version 9.1; SAS Institute, Cary, NC, USA).

\section{Results}

Descriptive analyses are presented in Table 1. In total, nine out of the 36 children were overweight or obese. Mean ages differed only

Table 1

Main characteristics of the study population by age group, sex and study centre (mean, SD and total numbers).

\begin{tabular}{|c|c|c|c|c|c|c|c|c|c|c|c|c|c|c|}
\hline & & \multirow{2}{*}{$\frac{\text { All }}{N}$} & & \multirow{2}{*}{$\frac{4-<6 \text { years }}{N}$} & & \multirow{2}{*}{\multicolumn{2}{|c|}{$\frac{6-<10 \text { years }}{N}$}} & \multirow{2}{*}{\multicolumn{2}{|c|}{$\frac{\text { Boys }}{N}$}} & \multirow{2}{*}{$\frac{\text { Girls }}{N}$} & & \multirow{2}{*}{$\frac{\text { Belgium }}{N}$} & & \multirow{2}{*}{$\frac{\text { Spain }}{N}$} \\
\hline & & & & & & & & & & & & & & \\
\hline Boys & & 17 & \multicolumn{2}{|r|}{6} & & \multicolumn{2}{|l|}{11} & \multicolumn{2}{|c|}{-} & - & & \multicolumn{2}{|l|}{2} & 15 \\
\hline Girls & & 19 & \multicolumn{2}{|r|}{8} & & 11 & & \multicolumn{2}{|c|}{-} & - & & \multicolumn{2}{|l|}{4} & 15 \\
\hline $4-<6$ years & & 14 & \multicolumn{2}{|r|}{-} & & - & & \multicolumn{2}{|c|}{6} & 8 & & \multicolumn{2}{|l|}{3} & 11 \\
\hline $6-<10$ years & & 22 & \multicolumn{2}{|r|}{-} & & - & & \multicolumn{2}{|c|}{11} & 11 & & \multicolumn{2}{|l|}{3} & 19 \\
\hline Thin $^{\mathrm{a}}$ & & 4 & \multicolumn{2}{|r|}{1} & & 3 & & \multicolumn{2}{|c|}{3} & 1 & & \multicolumn{2}{|l|}{1} & 3 \\
\hline Normal weight ${ }^{\mathrm{a}}$ & & 23 & \multicolumn{2}{|r|}{11} & & 12 & & \multicolumn{2}{|c|}{13} & 10 & & \multicolumn{2}{|l|}{4} & 19 \\
\hline Overweight $^{\mathrm{a}}$ & & 5 & \multicolumn{2}{|c|}{1} & & 4 & & \multicolumn{2}{|c|}{1} & 4 & & 1 & & 4 \\
\hline Obese $^{a}$ & & 4 & & 1 & & 3 & & & & 4 & & 0 & & 4 \\
\hline All & & 36 & & 14 & & 22 & & & & 19 & & 6 & & 30 \\
\hline & Mean & SD & Mean & SD & Mean & SD & Mean & SD & Mean & SD & Mean & SD & Mean & SD \\
\hline Age & 6.7 & 1.4 & 5.3 & 0.5 & 7.7 & 0.8 & 6.8 & 1.4 & 6.7 & 1.3 & 6.2 & 1.6 & 6.9 & 1.3 \\
\hline Weight (kg) & 24.4 & 5.0 & 20.9 & 2.8 & 26.6 & 4.9 & 22.8 & 3.6 & 25.8 & 5.7 & 22.7 & 4.7 & 24.7 & 5.1 \\
\hline Height $(\mathrm{cm})$ & 121.1 & 7.8 & 114.0 & 4.0 & 125.6 & 6.1 & 121.4 & 7.9 & 120.9 & 8.0 & 120.8 & 11.8 & 121.2 & 7.1 \\
\hline BMI $z$-score & 0.2 & 1.2 & -0.1 & 0.9 & 0.4 & 1.3 & -0.1 & 0.9 & 0.4 & 1.3 & -0.2 & 1.2 & 0.3 & 1.6 \\
\hline
\end{tabular}

SD: standard deviation.

Due to the small sample size the authors abstained from the presentation of percentages in the subgroups (sex, age, weight status, study centre).

a Cut-offs according to IOTF criteria. ${ }^{16}$ Prevalence of overweight not including obesity.

b Body mass index $z$-score according to Cole et al. ${ }^{17}$ 
Table 2

Mean energy expenditure (TEE), energy intake (EI), ratio of EI over TEE and difference between EI and TEE (bias) by age group, sex, study centre and weight status.

\begin{tabular}{|c|c|c|c|c|c|c|c|c|c|}
\hline & \multirow[t]{2}{*}{$N$} & \multicolumn{2}{|c|}{$\begin{array}{l}\mathrm{TEE}^{\mathrm{a}} \\
\text { (kcal/day) }\end{array}$} & \multicolumn{2}{|c|}{$\begin{array}{l}\mathrm{EI}^{\mathrm{a}} \\
(\mathrm{kcal} / \text { day })\end{array}$} & \multicolumn{2}{|c|}{$\begin{array}{l}\text { Ratio EI } \\
\text { over TEE }\end{array}$} & \multicolumn{2}{|c|}{$\begin{array}{l}\text { Bias }^{\mathrm{b}} \\
\text { (kcal/day) }\end{array}$} \\
\hline & & Mean & SD & Mean & SD & Mean & SD & Mean & SD \\
\hline $4-<6$ years & 14 & 1386 & 217 & 1273 & 352 & 0.95 & 0.35 & -113 & 460 \\
\hline $6-<10$ years & 22 & 1610 & 186 & 1645 & 465 & 1.02 & 0.27 & 35 & 431 \\
\hline Boys & 17 & 1574 & 219 & 1535 & 488 & 0.99 & 0.34 & -39 & 485 \\
\hline Girls & 19 & 1477 & 226 & 1469 & 440 & 1.00 & 0.28 & -8 & 412 \\
\hline Belgium & 6 & 1491 & 226 & 1434 & 290 & 0.96 & 0.11 & -57 & 154 \\
\hline Spain & 30 & 1530 & 228 & 1513 & 487 & 1.00 & 0.33 & -16 & 481 \\
\hline Thin/normal weight & 27 & 1513 & 231 & 1511 & 501 & 1.01 & 0.33 & -2 & 471 \\
\hline Overweight/obese & 9 & 1554 & 214 & 1468 & 313 & 0.96 & 0.23 & -86 & 356 \\
\hline All & 36 & 1523 & 225 & 1500 & 458 & 1.00 & 0.30 & -23 & 442 \\
\hline
\end{tabular}

a TEE: total energy expenditure; EI: energy intake.

b Mean difference between reported energy intake (means of two 24-HDR per child) and total energy expenditure (DLW measurements).

slightly between study centres and the sex distribution was almost balanced across the whole study group (17 boys, 19 girls) as well as across study centres.

As expected, TEE was higher in older children, higher in boys compared to girls and higher in overweight/obese compared to thin/normal weight children (Table 2) though differences in TEE were only small between the weight groups (thin/normal weight: $1513 \mathrm{kcal} /$ day; overweight/obese: $1554 \mathrm{kcal} /$ day). EI was again higher in older children as well as in boys but slightly lower in overweight/obese children compared to thin/normal weight children. Mean EI was lower compared to TEE by up to $5 \%(6-<10$ years) and higher by up to $2 \%$ ( $4-<6$ years) depending on the study group addressed. Regarding the total study group, the ratio of EI over TEE was 1.00 indicating that reported EI and measured TEE matched almost exactly (EI: $1500 \mathrm{kcal} /$ day; TEE: $1523 \mathrm{kcal} /$ day). The greatest difference between EI and TEE was found in children younger than six years (mean difference: $-113 \mathrm{kcal} /$ day), followed by the group of overweight/obese children (mean difference: $-86 \mathrm{kcal} / \mathrm{day})$.

The Bland-Altman plot (Fig. 2) revealed only moderate agreement between EI and TEE reflecting in particular the high day-today variation in dietary intakes. Individual differences between EI and TEE varied widely, ranging from -836 up to $+953 \mathrm{kcal} /$ day. The largest bias was observed in case of very low mean values of EI and

All

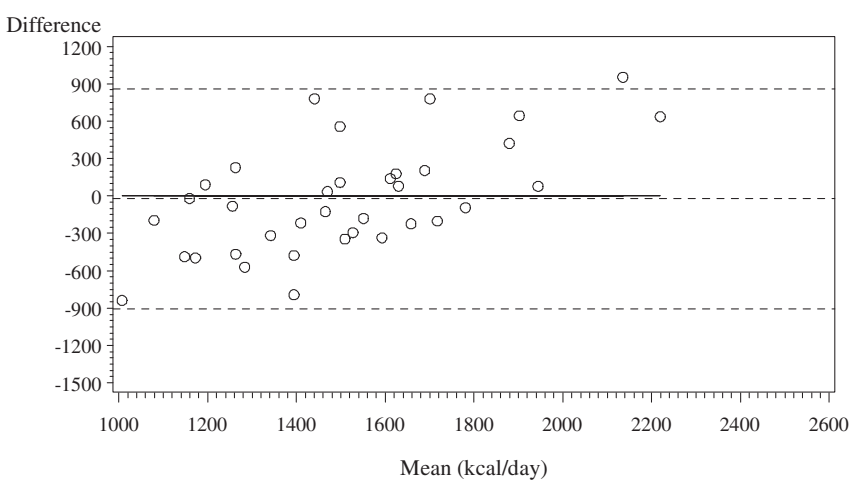

Fig. 2. Bland-Altman plot agreement between measured energy expenditure (TEE; $\mathrm{kcal} /$ day) and reported energy intake (EI; kcal/day). The mean of EI and TEE is plotted on the $x$-axis, the difference of both values (bias) on the $y$-axis accordingly. The solid line indicates the line of total agreement (zero differences between EI and TEE). Mean difference and upper/lower limits of agreement (mean difference \pm 2 SD) are superimposed by broken line.
Table 3

Number of low-energy-reports (LER), adequate reports (AER) and high-energyreports (HER) by age group, sex, study centre and weight status.

\begin{tabular}{|c|c|c|c|}
\hline & $\begin{array}{l}\text { Low-energy- } \\
\text { reports }^{\text {b }}\end{array}$ & $\begin{array}{l}\text { Adequate } \\
\text { reports }^{c}\end{array}$ & $\begin{array}{l}\text { High-energy- } \\
\text { reports }^{\mathrm{d}}\end{array}$ \\
\hline & $N$ & $N$ & $N$ \\
\hline Total study group & $3(8 \%)$ & $28(78 \%)$ & $5(14 \%)$ \\
\hline $4-<6$ years & 2 & 10 & 2 \\
\hline $6-<10$ years & 1 & 18 & 3 \\
\hline Boys & 2 & 13 & 2 \\
\hline Girls & 1 & 15 & 3 \\
\hline Belgium & 0 & 6 & 0 \\
\hline Spain & 3 & 22 & 5 \\
\hline Thin $^{\mathrm{a}}$ & 1 & 3 & 0 \\
\hline Normal weight $^{\mathrm{a}}$ & 2 & 17 & 4 \\
\hline Overweight $^{\mathrm{a}}$ & 0 & 4 & 1 \\
\hline Obese $^{a}$ & 0 & 4 & 0 \\
\hline
\end{tabular}

Due to the small sample size the authors abstained from the presentation of percentages in the subgroups.

a Cut-offs according to IOTF criteria. ${ }^{23}$ Prevalence of overweight not including obesity.

b Low-energy-reporters defined as: EI/TEE $<0.65$ (boys), EI/TEE $<0.66$ (girls).

${ }^{\text {c }}$ Adequate reports defined as: $0.65 \leq \mathrm{EI} / \mathrm{TEE}<1.35$ (boys), $0.66 \leq \mathrm{EI} / \mathrm{TEE}<1.34$ (girls).

${ }_{\mathrm{d}}$ High-energy-reports defined as: EI/TEE $\geq 1.35$ (boys), EI/TEE $\geq 1.34$ (girls).

TEE (mainly negative bias, EI $<$ TEE), as well as in case of very high mean values of EI and TEE (mainly positive bias, EI $>$ TEE).

The cut-off technique identified five HER (14\%) and three LER (8\%) (Table 3). Mean TEE was highest in the group of LER whereas, as expected, EI was lowest (Table 4). Fat intakes expressed as percentage of total EI were slightly lower in LER compared to AER and highest in HER whereas the opposite was found for percentages of EI from carbohydrates. Percentages of EI from proteins were lowest in AER. Intakes in g per day were lowest in LER and highest in HER for all macronutrients and water.

In the subgroup analysis of the exclusively obese Swedish children that had previously been treated in an obesity clinic (not included in the tables), a mean difference between EI and TEE of $-455 \mathrm{kcal} / \mathrm{day}$ was observed and seven out of the ten Swedish children were classified as LER.

\section{Discussion}

The present study aimed to evaluate the accuracy of EI estimated from two repeated 24-HDR using objective measurements of TEE obtained by the gold-standard technique DLW. ${ }^{2}$ Results revealed good agreement between EI and TEE for the total study group as well as in subgroups of age, sex, study centre and weight status; Mean EI was lower compared to mean TEE by up to $5 \%$ and higher by up to $2 \%$ depending on the study group addressed. Considering the whole sample, the mean ratio of reported EI over TEE equalled one which means that both values agreed almost exactly on group level. Previous studies in children found underreporting of EI relative to TEE ranging from $19 \%$ to $41 \%$ and overreporting ranging from $7 \%$ to $11 \% .{ }^{9}$ However, findings strongly vary depending on the participants' age and on the dietary assessment method used. ${ }^{22-24}$ The good agreement between EI and TEE in our study may be explained by the additional assessment of school meals which may have reduced reporting errors caused by meals not under parental control. Furthermore, the display of pictures with increasing portion sizes on the screen may have improved the estimation of portion sizes. However, also restricting on a convenience study sample may have contributed to these results as it is likely that the participants were highly-motivated.

Even in overweight/obese children, a group that has repeatedly been reported to be strongly influenced by misreporting, ${ }^{8,25}$ only a 
Table 4

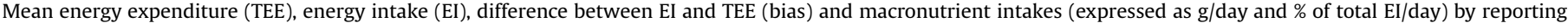
group (low-energy-report, adequate report and high-energy-report).

\begin{tabular}{|c|c|c|c|c|c|c|c|c|}
\hline & \multicolumn{2}{|c|}{ Low-energy-reports ${ }^{c}$} & \multicolumn{2}{|c|}{ Adequate-energy-reports ${ }^{\mathrm{d}}$} & \multicolumn{2}{|c|}{ High-energy-reports ${ }^{\mathrm{e}}$} & \multicolumn{2}{|c|}{ Total study group } \\
\hline & Mean & SD & Mean & SD & Mean & SD & Mean & SD \\
\hline $\mathrm{TEE}^{\mathrm{a}}$ (kcal/day) & 1595 & 183.9 & 1544 & 219.0 & 1364 & 252.9 & 1523 & 225.0 \\
\hline $\mathrm{El}^{\mathrm{a}}$ (kcal/day) & 862 & 236.4 & 1460 & 367.9 & 2107 & 336.9 & 1500 & 457.6 \\
\hline $\operatorname{Bias}^{\mathrm{b}}$ (kcal/day) & -733 & 142.7 & -84 & 282.2 & 743 & 150.6 & -22.9 & 441.8 \\
\hline Carbohydrate intake (g/day) & 89.4 & 14.1 & 152.8 & 50.7 & 187.1 & 39.3 & 152.3 & 51.8 \\
\hline \%EI from carbohydrates & 43.3 & 6.9 & 42.2 & 7.4 & 35.9 & 3.7 & 41.4 & 7.2 \\
\hline Fat intake (g/day) & 37.5 & 13.3 & 65.0 & 19.9 & 99.4 & 17.7 & 67.5 & 24.1 \\
\hline$\%$ EI from fat & 37.8 & 3.9 & 39.4 & 7.3 & 41.8 & 5.0 & 39.6 & 6.8 \\
\hline Protein intake (g/day) & 41.9 & 16.7 & 66.3 & 17.3 & 116.8 & 34.6 & 71.3 & 27.8 \\
\hline \%EI from proteins & 19.3 & 3.4 & 18.7 & 3.4 & 22.5 & 5.7 & 19.3 & 3.9 \\
\hline Water intake (g/day) & 824.8 & 386.4 & 1176 & 398.5 & 1733 & 587.7 & 1224 & 472.4 \\
\hline
\end{tabular}

a TEE, total energy expenditure; EI, energy intake.

b Mean difference between reported energy intake (means of two 24-HDR per child) and total energy expenditure (DLW measurements).

c Low-energy-reporters defined as: EI/TEE $<0.65$ (boys), EI/TEE $<0.66$ (girls).

d Adequate reports defined as: $0.65 \leq \mathrm{EI} / \mathrm{TEE}<1.35$ (boys), $0.66 \leq \mathrm{EI} / \mathrm{TEE}<1.34$ (girls).

e High-energy-reports defined as: $\mathrm{EI} / \mathrm{TEE} \geq 1.35$ (boys), EI/TEE $\geq 1.34$ (girls).

mean difference of $-84 \mathrm{kcal} /$ day was observed between reported EI and measured TEE in our data. Forrestal ${ }^{8}$ stated in a review that higher weight, obesity and BMI had consistently been associated with low-energy-reporting at all ages. In proxy-reports, misreporting (comprising low- and high-energy-reporting) may to a large extent be explained by meals not under parental control and difficulties in estimation of portion sizes, but also by intentional misreporting due to social desirability bias. The lower percentages of EI from fat but higher percentages of EI from carbohydrates in LER may indicate selective omission of certain foods high in fat and protein, although the exact nature of these differences cannot be determined with available methodologies. No study was found investigating socially desirable answer behaviour in proxy-reports in that age group. Social desirability was shown to be a predictor of misreporting among adults, ${ }^{26}$ so it can be hypothesised that parents feeling ashamed for their child's unhealthy/energy-dense diet may intentionally misreport in proxy-reports as well. Inconsistently with literature, children classified as LER were either thin or normal weight in our data. It can be assumed that these lowenergy-reports rather reflect exceptional days (e.g. child was ill) or reporting errors caused by meals not under parental control than intentional misreporting. In addition, by use of a cut-off approach, underreporting cannot be distinguished from a hypocaloric diet (undereating). Thus, participants classified as LER may not be underreporting but following a specific diet. In these children, EI values may actually be lower than TEE so that the proxy-report may still be valid. However, when investigating diet-disease associations these cases might still bias the true diet-disease association as their current diet (exceptional days) might not be the cause of their current health or weight status.

To the authors' knowledge, child-specific cut-off values to classify 24-HDR in different reporting groups were only applied in a study comparing EI to estimated basal metabolic rates ${ }^{22}$ making it difficult to compare proportions of LER, AER and HER to other studies.

Differences between EI and TEE were large at the individual level (regarding single children's values), whereas on group level (mean EI vs. mean TEE) good agreement was observed. For example in thin/normal weight children means of EI and TEE (EI: $1511 \mathrm{kcal} /$ day; TEE: $1513 \mathrm{kcal} /$ day) almost coincide although individual differences between EI and TEE strongly differ from zero ( $-836 \mathrm{kcal} /$ day up to $+953 \mathrm{kcal} /$ day). This may be explained by random errors including day-to-day variation that cancel out on group level. These results agree with other studies reporting biases at the individual level, but better agreement on group level. ${ }^{23,27-29}$
The large difference between reported EI and measured TEE (mean difference: $-455 \mathrm{kcal} /$ day) that was observed in the Swedish subgroup may be a consequence of previous treatment in the obesity clinic resulting in changes in lifestyle behaviours including eating habits and leisure time activities. Also intentional or unintentional underreporting of energy intake by the parents of these obese children may have contributed to these findings.

In adults, a combination of methods (two non-consecutive 24HDR interviews in combination with a food frequency questionnaire (FFQ)) to measure dietary intake has been recommended for use in monitoring and epidemiological surveys (EFCOVAL \& IDAMES project: 2 EC 6th FP). ${ }^{30}$ However, recommendations for measuring dietary intake among children are still lacking but it can be hypothesised that additional FFQ information may help to improve the estimation of individual intakes in childhood populations as well.

\subsection{Limitations and strengths}

The relatively small sample size and correspondingly low power is a limitation and was also the reason to abstain from statistical testing for differences between groups. However, the sample size is consistent with numbers in other validation studies using the costintense doubly labeled water technique. Furthermore, only approximate agreement between EI and TEE can be expected when assessing only two 24-HDR per child due to the large day-to-day variability in EI. Moreover, the cut-off technique aims only to identify under-/overestimations resulting in physiologically implausible $\mathrm{El}^{24}$ and does not allow distinction between various degrees of misreporting or to differentiate between underreporting and undereating. As a convenience sample was chosen, a selection bias of highly motivated parents and children cannot be precluded.

To the authors' knowledge, this is among the first studies documenting accuracy of parental reporting using objective measurements of TEE. A strength is the assessment of EI and TEE within the same time frame, ${ }^{9}$ increasing the reliability of the measurements. In addition, the assessment of school meals enhanced the completeness of the 24-HDR and the display of pictures with increasing portion sizes in the SACINA program simplified the estimation of portion sizes for the respondents.

\subsection{Conclusions}

In summary, good agreement between proxy-reported EI and measured TEE was observed on group level - even in overweight/ 
obese children - whereas individual differences between both values varied widely. Two proxy-reported 24-HDR including visual aids and school meal reporting are a valid measure for EI on group level but not sufficient to evaluate individual intakes. Future research is required to improve the precision of proxy-reported EI for individual children.

\section{Ethical statement}

The study was approved by the appropriate ethics committees in each centre, specifically by the "Comité Ético de Investigación Clínica de Aragón (CEICA)" in Spain, the Ethical Committee of the Ghent University Hospital in Belgium, and the "Regionala Etikprövningsnämnden i Göteborg" in Sweden.

\section{Conflict of interest}

All the authors declare that there are no conflicts of interest.

\section{Acknowledgements}

This manuscript represents original work that has not been published previously and is currently not considered by another journal. The authors confirm that the manuscript will not be published elsewhere in the same form, in English or in any other language, if it is accepted by Clinical Nutrition.

Each author has seen and approved the contents of the submitted manuscript. All authors contributed to conception and design, acquisition of data, analysis or interpretation of data. Final approval of the version published was given by all the authors. In detail: C. Börnhorst and S. Bel-Serrat drafted the manuscript; IP, KB, IH, SDH, GE, LL, KW and LAM conceived the study and participated in its design and coordination; IH, IP and LAM helped drafting the manuscript and interpreting the data; all the authors revised the article critically for important intellectual content.

This work was done as part of the IDEFICS Study (www.idefics. eu) and is published on behalf of its European Consortium. We gratefully acknowledge the financial support of the European Community within the Sixth RTD Framework Programme Contract No. 016181 (FOOD). The information in this document reflects the author's view and is provided as is.

SBS was funded by a grant from the Aragón's Regional Government (Diputación General de Aragón, DGA). IS was financially supported by the Research Foundation - Flanders (Grant $\mathrm{n}^{\circ}$ : 1.2.683.11.N.00).

\section{References}

1. Moreno LA, Rodriguez G. Dietary risk factors for development of childhood obesity. Curr Opin Clin Nutr Metab Care 2007;10(3):336-41.

2. Schoeller DA. Validation of habitual energy intake. Public Health Nutr 2002;5(6A):883-8.

3. Schoeller DA. Measurement of energy expenditure in free-living humans by using doubly labeled water. J Nutr 1988;118(11):1278-89.

4. Kuzawa CW. Adipose tissue in human infancy and childhood: an evolutionary perspective. Am J Phys Anthropol 1998;(Suppl. 27):177-209.

5. Livingstone MB, Black AE. Markers of the validity of reported energy intake. J Nutr 2003;133(Suppl. 3):895S-920S.
6. Livingstone MB, Robson PJ. Measurement of dietary intake in children. Proc Nutr Soc 2000;59(2):279-93.

7. Willet W. Nutritional epidemiology. 1st ed. New York, NY: Oxford University Press; 1990.

8. Forrestal SG. Energy intake misreporting among children and adolescents: a literature review. Matern Child Nutr 2011;7(2):112-27.

9. Burrows TL, Martin RJ, Collins CE. A systematic review of the validity of dietary assessment methods in children when compared with the method of doubly labeled water. J Am Diet Assoc 2010;110(10):1501-10.

10. Huang TT, Roberts SB, Howarth NC, McCrory MA. Effect of screening out implausible energy intake reports on relationships between diet and BMI. Obes Res 2005;13(7):1205-17.

11. Bammann K, Sioen I, Huybrechts I, Casajus JA, Vicente-Rodriguez G, Cuthill R et al. The IDEFICS validation study on field methods for assessing physical activity and body composition in children: design and data collection. Int J Obes 2011;35(Suppl. 1):S79-87.

12. Westerterp KR, Wouters L, van Marken Lichtenbelt WD. The Maastricht protocol for the measurement of body composition and energy expenditure with labeled water. Obes Res 1995;3(Suppl. 1):49-57.

13. Schoeller DA, Ravussin E, Schutz Y, Acheson KJ, Baertschi P, Jequier E. Energy expenditure by doubly labeled water: validation in humans and proposed calculation. Am J Physiol 1986;250(5 Pt 2):R823-30.

14. Vereecken CA, Covents M, Matthys C, Maes L. Young adolescents' nutrition assessment on computer (YANA-C). Eur J Clin Nutr 2005;59(5):658-67.

15. Hebestreit A, Eiben G, Brünings-Kuppe C, Huybrechts I. Computer based 24 hour dietary recall: the SACINA program. In: Bammann K, Ahrens W, editors. Measurement tools for a health survey on Nutrition, physical activity and lifestyle in children: the European idefics study. 1st ed. Berlin, Germany: Springer; 2012. In Press.

16. Cole TJ, Bellizzi MC, Flegal KM, Dietz WH. Establishing a standard definition for child overweight and obesity worldwide: international survey. BMJ 2000;320(7244):1240-3.

17. Cole TJ, Freeman JV, Preece MA. Body mass index reference curves for the UK, 1990. Arch Dis Child 1995;73(1):25-9.

18. Bland JM, Altman DG. Statistical methods for assessing agreement between two methods of clinical measurement. Lancet 1986;1(8476):307-10.

19. Sjoberg A, Slinde F, Arvidsson D, Ellegard L, Gramatkovski E, Hallberg L, et al Energy intake in Swedish adolescents: validation of diet history with doubly labelled water. Eur J Clin Nutr 2003;57(12):1643-52.

20. Black AE, Cole TJ. Within- and between-subject variation in energy expenditure measured by the doubly-labelled water technique: implications for validating reported dietary energy intake. Eur J Clin Nutr 2000;54(5):386-94.

21. Nelson M, Black AE, Morris JA, Cole TJ. Between- and within-subject variation in nutrient intake from infancy to old age: estimating the number of days required to rank dietary intakes with desired precision. Am J Clin Nutr 1989;50(1):155-67.

22. Sichert-Hellert W, Kersting M, Schoch G. Underreporting of energy intake in 1 to 18 year old German children and adolescents. Z Ernahrungswiss 1998;37(3): 242-51.

23. Montgomery C, Reilly JJ, Jackson DM, Kelly LA, Slater C, Paton JY, et al. Validation of energy intake by 24-hour multiple pass recall: comparison with total energy expenditure in children aged 5-7 years. Br J Nutr 2005;93(5):671-6.

24. Haraldsdottir J, Sandstrom B. Detection of underestimated energy intake in young adults. Int J Epidemiol 1994;23(3):577-82.

25. Fisher JO, Johnson RK, Lindquist C, Birch LL, Goran MI. Influence of body composition on the accuracy of reported energy intake in children. Obes Res 2000;8(8):597-603.

26. Scagliusi FB, Ferriolli E, Pfrimer K, Laureano C, Cunha CS, Gualano B, et al Characteristics of women who frequently under report their energy intake: a doubly labelled water study. Eur J Clin Nutr 2009;63(10):1192-9.

27. Reilly JJ, Montgomery C, Jackson D, MacRitchie J, Armstrong J. Energy intake by multiple pass $24 \mathrm{~h}$ recall and total energy expenditure: a comparison in a representative sample of 3-4-year-olds. Br J Nutr 2001;86(5):601-5.

28. Johnson RK, Driscoll P, Goran MI. Comparison of multiple-pass 24-hour recall estimates of energy intake with total energy expenditure determined by the doubly labeled water method in young children. J Am Diet Assoc 1996;96(11): 1140-4.

29. O'Connor J, Ball EJ, Steinbeck KS, Davies PS, Wishart C, Gaskin KJ, et al. Comparison of total energy expenditure and energy intake in children aged 6-9 y. Am J Clin Nutr 2001;74(5):643-9.

30. de Boer EJ, Slimani N, van 't Veer P, Boeing H, Feinberg M, Leclercq C, et al. The European food consumption validation project: conclusions and recommendations. Eur J Clin Nutr 2011;65(Suppl. 1):S102-7. 